\title{
Preserving nickel electrode conductivity during sintering process using lithium carbonate
} coatings

\author{
* Damoon Sohrabi Baba Heidary and Clive A. Randall \\ Center for Dielectrics and Piezoelectrics, Materials Research Institute, the Pennsylvania State University, \\ University Park, PA 16802, USA \\ *Corresponding author; Email: dus255@psu.edu; Phone: +1-917-376-7737
}

\begin{abstract}
The resistance of nickel particles can be decreased by five orders of magnitude when coated with lithium carbonate during sintering in an oxidative atmosphere. The resistance is within a range, in which use is suitable for electrodes in the electroceramic devices. The coated powders have the potential to replace the precious metals (e.g. Pt and $\mathrm{Ag}$ ) in multilayer electroceramic devices. A systematic study of the influence of sintering atmosphere and temperature on the morphology of $\mathrm{Li}_{2} \mathrm{CO}_{3}$-coated $\mathrm{Ni}$ particles was investigated via TEM (transmission electron microscopy), SEM-FIB (scanning electron microscopy focused ion beam) imaging, and TGA (thermogravimetric analysis). The results suggested that the $\mathrm{Li}_{2} \mathrm{CO}_{3}$ decomposes and produces $\mathrm{CO}$ in the presence of residual carbon; $\mathrm{CO}$, as a reducing agent, decreases the amount of $\mathrm{NiO}$ phases formed during sintering. At the same time, the $\mathrm{NiO}$ phase was doped with $\mathrm{Li}^{+}$, resulting in a decrease in its resistivity. The combination of these two processes decreased the resistance of the final $\mathrm{Ni}$ electrodes from $140 \mathrm{k} \Omega$ to $1 \Omega$. The effect and role of these two mechanisms were separated, and it is shown that both of them are equally useful in the preservation of electrical conductivity.
\end{abstract}

Keywords: Nickel; conductivity; lithium; EELS; decomposition; electrode

\section{Introduction}


Nickel electrodes have been frequently used in electroceramic devices, such as co-fired capacitive devices, multilayer lead free piezoelectrics ${ }^{1-3}$ and solid oxide fuel cells $\mathrm{s}^{4,5}$. To protect Ni from oxidation, a heavily reducing atmosphere e.g. $P_{O_{2}}=10^{-10}$ atm should be used ${ }^{6}$. This atmosphere introduces a large number of oxygen vacancies to the system, which reduce the insulation resistance properties and also the life time of devices ${ }^{7,8}$. In addition, to obtain an atmosphere with an oxygen partial pressure in order of $10^{-10} \mathrm{~atm}$, hydrogen gas should be used as a reducing agent. It was demonstrated that hydrogen can diffuse into electroceramic devices and degrade their insulation properties ${ }^{9-12}$. In order to avoid these shortcomings, one solution is to sinter the devices in less reducing atmosphere, e.g. $P_{O_{2}}=10^{-4}$ atm, without using hydrogen and, on the other hand, using some measurements to preserve Ni electrode conductivity. In the previous paper ${ }^{13}$, it was illustrated that the resistance of Ni electrode can be kept as low as $1 \Omega$ by coating $\mathrm{Li}_{2} \mathrm{CO}_{3}$ around $\mathrm{Ni}$ particles after sintering at $P_{\mathrm{O}_{2}}=10^{-4}$ atm, while the resistance of the uncoated particle was $140 \mathrm{k} \Omega$ after sintering under the same conditions. Although the $\mathrm{Li}_{2} \mathrm{CO}_{3}$ coatings show promising potential in preserving Ni particle conductivity, the mechanism behind the conductivity preservation still needs to be explored.

Two mechanisms were speculated as being responsible for the conductivity preservation in this study. First, the lithium carbonate can decompose in the course of the sintering process and produce CO gas in the presence of carbon ${ }^{13,14}$. $\mathrm{CO}$ gas is a reducing agent and can decrease $\mathrm{pO}_{2}$ locally. The source of carbon is the organic materials used in making the electrode paste ${ }^{15,16}$. The second mechanism is to dope the $\mathrm{NiO}$ phase in the electrodes with $\mathrm{Li}^{+}$in order to increase the $\mathrm{Ni}^{3+} / \mathrm{Ni}^{2+}$ ratio and encourage electronic polaron hopping between them ${ }^{17,18}$. Depending on the amount of oxygen, nickel oxide has the possibility of non-stoichiometric defects with Ni vacancies $\left(V_{N i}^{\prime \prime}\right)^{19-23} \cdot V_{N i}^{\prime \prime}$ introduces negative charge to the lattice, which would be compensated by changing the oxidation state of some $\mathrm{Ni}$ ions from $2+$ to $3+$. The mixture of $\mathrm{Ni}^{3+}$ and $\mathrm{Ni}^{2+}$ enables electron hopping between those ions ${ }^{24}$. Thus, one can argue that the conductivity of $\mathrm{NiO}$ phases can be manipulated by changing the $\mathrm{Ni}^{3+} / \mathrm{Ni}^{2+}$ ratio through doping. In the 
previous work ${ }^{25}$, it was illustrated that the resistance of Ni foils after a heat treatment in air can be changed from $1 \mathrm{G} \Omega$ doped with $\mathrm{Al}^{3+}$ to $2 \mathrm{M} \Omega$ doped with $\mathrm{Zn}^{2+}$. An EELS (electron energy loss spectroscopy) analysis showed that the ratio of $\mathrm{Ni}^{3+} / \mathrm{Ni}^{2+}$ in the $\mathrm{Zn}^{2+}$-doped foil is larger than the $\mathrm{Al}^{3+}$ doped foil. If this is the case, $\mathrm{Li}^{+}$will be a good candidate to dope the NiO phase, since $\mathrm{Li}^{+}$doping can disturb charge neutrality more and increase the $\mathrm{Ni}^{3+} / \mathrm{Ni}^{2+}$ ratio more effectively. In addition, among the alkali cations, $\mathrm{Li}^{+}$has the closest ionic radius to $\mathrm{Ni}$ ions, and it is expected to have the highest diffusion coefficient in $\mathrm{NiO}$ crystals. $\mathrm{Li}^{+}$and $\mathrm{Ni}^{2+}$ ionic radius are 76 and $69 \mathrm{pm}^{26}$. In addition, the other authors have reported the decrease in $\mathrm{NiO}$ resistivity due to $\mathrm{Li}^{+}$doping ${ }^{27,28}$.

In the previous paper ${ }^{13}$, a simple and innovative method to coat $\mathrm{Li}_{2} \mathrm{CO}_{3}$ on $\mathrm{Ni}$ particles was introduced, and it was illustrated that the coating is able to effectively preserve $\mathrm{Ni}$ electrode conductivity. In this paper, a systematic study on microstructures of $\mathrm{Ni}$ electrodes during decomposition and the atom distribution in the $\mathrm{Ni}$ electrodes was executed to explore the mechanisms that are responsible for conductivity preservation.

\section{Experimental Section}

In order to coat Ni particles, the $\mathrm{Li}_{2} \mathrm{CO}_{3}$ powder was dissolved into deionized water, and then Ni particles were added and stirred to make sure of full wettability of Ni particles. Next, the mixture was heated to evaporate the liquid, while it was mechanically stirred during the entire process. The solution reached saturation, and the chemical compound started to deposit on Ni particles. More detail about the coating process is given in Supporting Information and in the previous paper ${ }^{13}$.

The $\mathrm{Li}_{2} \mathrm{CO}_{3}$ was bought from Alfa Aesar in powder form, with $99.998 \%$ purity. The Ni powder was the courtesy of JFE Mineral Company and Shoei Chemical, with the average particle size of $300 \mathrm{~nm}$ and purity of $99+\%$. If it did not specify in the text, 17.3 wt\% of $\mathrm{Li}_{2} \mathrm{CO}_{3}$ was used for coating Ni particles. 
6 grams of the coated particles were mixed with 1 gram of the 15 wt.\% ethyl cellulose solved in dihydro terpineol. The final product was a liquid mixture with a high viscosity, commonly referred to as "electrode ink". Then the ink was painted on a piece of $1 \mathrm{~cm}$ by $0.5 \mathrm{~cm}$ alumina sheet and dried at $120^{\circ} \mathrm{C}$ for 20 minutes. After that, the alumina sheets were exposed to different heat treatments at different atmospheres. The heating and cooling rates were $100{ }^{\circ} \mathrm{C} / \mathrm{min}$ and $-50^{\circ} \mathrm{C} / \mathrm{min}$, obtained by a homemade fast-heating furnace ${ }^{29}$. The sintered particles were referred as "sheet" in this paper. The nitrogen and carbon dioxide gases have the purity of $99.999 \%$ and $99.99 \%$, respectively. The source of oxygen was the cylinder with $0.1 \%$ oxygen balanced with nitrogen.

The electrical resistance measurement was executed by a two-probe method and was explained elsewhere ${ }^{13}$. The SEM (scanning electron microscope) micrographs and TEM (transmission electron microscope) samples were obtained by FEI Helios NanoLab 660 FIB/SEM. The TEM analysis was done by FEI TALOS F200X and TECNAI G20, equipped with EELS (electron energy loss spectroscopy). The TGA (thermogravimetric analysis) tests were done by TA Instrument SDT Q600.

\section{Results and discussion}

As mentioned earlier, two phenomena of $\mathrm{Li}_{2} \mathrm{CO}_{3}$ decomposition and $\mathrm{Li}^{+}$effect are effective in the conductivity preservation of $\mathrm{Ni}$ electrodes. These two phenomena were studied separately, and an effort was made to separate their influences.

\subsection{Lithium Carbonate decomposition}

Lithium carbonate decomposed into $\mathrm{Li}_{2} \mathrm{O}$ and $\mathrm{CO}_{2}$ around $763^{\circ} \mathrm{C}$, based on TGA (thermogravimetric analysis) tests in Supporting Information. Subsequently, $\mathrm{CO}_{2}$ would be converted to $\mathrm{CO}$ in the presence of carbon ${ }^{14,30}$. The next reaction in low partial pressure of oxygen and the presence of $\mathrm{Ni}$ as a catalyst could be the CO decomposition to oxygen and carbon ${ }^{13}$. In Supporting Information, it was demonstrated that the peak of the maximum weight loss in TGA tests due to the decomposition reaction can be 
pushed back from $819^{\circ} \mathrm{C}$ in air to $1086^{\circ} \mathrm{C}$ in nitrogen and $1235^{\circ} \mathrm{C}$ in carbon dioxide. Also, the results suggest that the decomposition rate of pure $\mathrm{Li}_{2} \mathrm{CO}_{3}$ powders would be significantly different in $\mathrm{CO}_{2}$ and nitrogen atmosphere. The effect of sintering atmosphere was discussed in more details in Supporting Information. For instance, applying $\mathrm{CO}_{2}$ atmosphere during sintering could hinder the first reaction (i.e. producing $\mathrm{CO}_{2}$ gas) in the chain of the decomposition process; due to the extra $\mathrm{CO}_{2}$ gas, the reaction would be reluctant to proceed to the right and produce more $\mathrm{CO}_{2}$ gas, based on Le Chatelier's principle. In other words, $\mathrm{Li}_{2} \mathrm{CO}_{3}$ can be preserved in $\mathrm{CO}_{2}$ atmosphere up to $1235^{\circ} \mathrm{C}$. Thus, one may conclude that the $\mathrm{Li}_{2} \mathrm{CO}_{3}$ decomposition can be manipulated by applying different sintering atmosphere.

The lithium carbonate decomposition was investigated by heating the coated particles to $900{ }^{\circ} \mathrm{C}$ and cooling down without holding at five different atmospheres of $\mathrm{CO}_{2}$, pure nitrogen, $0.02 \%$ oxygen, $0.04 \%$ oxygen, and air. The SEM micrographs of the FIB cross section of these sheets are presented in Figure 1. The microstructure of the sheet, exposed to $900{ }^{\circ} \mathrm{C}$ in $\mathrm{CO}_{2}$, is presented in Figure 1 (a). Based on the discussion above, this micrograph can represent the mixture of $\mathrm{Ni}$ and $\mathrm{Li}_{2} \mathrm{CO}_{3}$ in the early stage of sintering, as if there is no $\mathrm{Li}_{2} \mathrm{CO}_{3}$ decomposition. As shown in the micrograph, the $\mathrm{Li}_{2} \mathrm{CO}_{3}$ without decomposition is able to melt and surround all $\mathrm{Ni}$ grains; one can consider that as a liquid phase sintering, in which one compound gets melted at the beginning of sintering and surrounds the grains of the second powder ${ }^{31,32}$. In addition, since there is an unlimited source of $\mathrm{CO}_{2}$ due to blowing $\mathrm{CO}_{2}$ gas into the chamber, all the residual carbon would be eliminated by $\mathrm{CO}_{2(g)}+C_{(s)} \rightarrow 2 \mathrm{CO}_{(g)}$ in the early stage of sintering ${ }^{33}$.

Figure 1 (b) shows the micrograph of the sheet, sintered under pure nitrogen. There is a thick layer of carbon on the top of the sheet. In the absence of an unlimited source of $\mathrm{CO}_{2}$ gas and the presence of residual carbon, $\mathrm{Li}_{2} \mathrm{CO}_{3}$ decomposed to $\mathrm{CO}$. In the next set of reactions, due to the lack of oxygen, $\mathrm{CO}$ 
decomposed and redeposited carbon on Ni particles at the top of the sheet based on Eq.1 $1^{33-35}$. More evidence is provided elsewhere ${ }^{13}$ and also in Figure S4, presented the TEM analyses of the carbon layer.

$$
2 C_{(s)}+O_{2(g)} \stackrel{N i}{\leftrightarrow} 2 C O_{(g)}
$$

\section{Eq.1}

Now, oxygen would be added to the scenario and increased to 0.02 and 0.04 vol.\% and, eventually, air; the microstructure of the sheets is respectfully presented in Figure 1 (c) to (e). The thickness of the carbon layer on the top of the sheets, sintered in nitrogen, 0.02 , and 0.04 vol.\%, were measured 2.29, 2.0, and $1.6 \mu \mathrm{m}$ on average, and it disappeared in air. This suggests that the carbon re-deposition decreases by increasing oxygen and, eventually, it becomes zero in air. That observation fits well with the explanation of Eq.1, in which it is suggested that increase in the amount of oxygen drives the equilibrium to the right and prevents carbon re-deposition.

The other observation is that, by increasing the amount of oxygen from pure nitrogen to air, the amount of weight loss increases and as a result, the space between individual $\mathrm{Ni}$ grains would increase. The trend of this phenomenon can be traced in Figure $1(b)$ to (e). There is a small number of the isolated $\mathrm{Ni}$ grains on the top of the cross section in Figure 1 (c); their number increased by increasing the oxygen flow from 0.02 to $0.04 \%$ oxygen, and they overcame the entire cross section in air, as shown in Figure 1 (d) and (e). This is due to the fact that the $\mathrm{Li}_{2} \mathrm{CO}_{3}$ can lose up to $59 \%$ of its original weight during the decomposition process. On the other hand, the system can simultaneously compensate some of the weight loss by the carbon re-deposition. Increasing the oxygen flow would hinder the carbon redeposition process and weight loss would be manifested as the empty space between the grains. To verify this explanation, the amount of $\mathrm{Li}_{2} \mathrm{CO}_{3}$ decreased from 17.3 wt.\% to 3.4 wt.\% in the coating process, and the resultant particles heated to $900{ }^{\circ} \mathrm{C}$ in air. The cross-section of this sheet is presented in Figure S6. It can be seen that the empty space between grains decreased significantly due to the 
decrease in the $\mathrm{Li}_{2} \mathrm{CO}_{3}$ percentage and, consequently, the weight loss. Furthermore, a similar conclusion can be reached from TGA tests in Supporting Information.

Now, the importance of Figure 1 (a) can be better appreciated. Since $\mathrm{CO}_{2}$ prevented $\mathrm{Li}_{2} \mathrm{CO}_{3}$ decomposition and eliminated residual carbon, Figure 1 (a) shows the ideal case of neither the $\mathrm{Li}_{2} \mathrm{CO}_{3}$ decomposition nor the carbon re-deposition; the $\mathrm{Li}_{2} \mathrm{CO}_{3}$ coating only melted and enclosed $\mathrm{Ni}$ grains. In the mixture of oxygen and nitrogen gas, on the other hand, $\mathrm{Li}_{2} \mathrm{CO}_{3}$ did the same thing, but it was simultaneously decomposed. However, the decomposition is not necessarily a harmful process, since it produces $\mathrm{CO}$ gas and limits the $\mathrm{NiO}$ phase formation during the sintering process, as will be discussed in more details later.

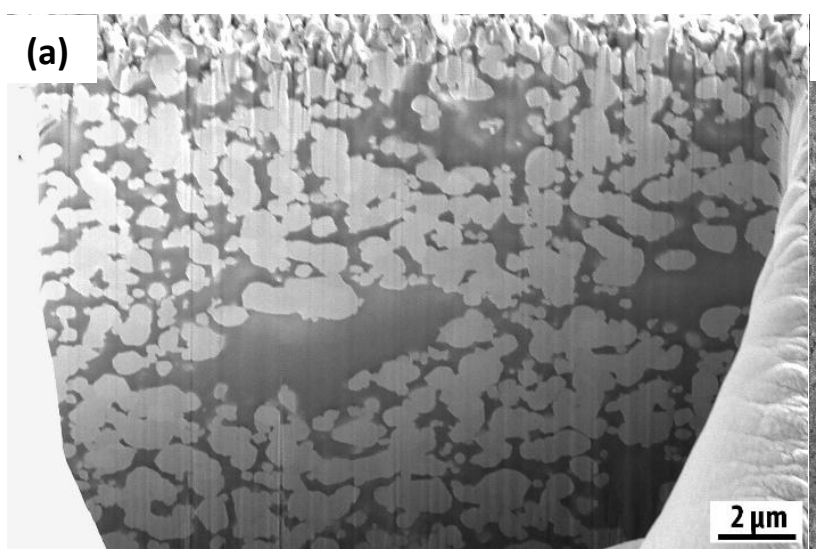

\section{(b)}

\section{(c)}

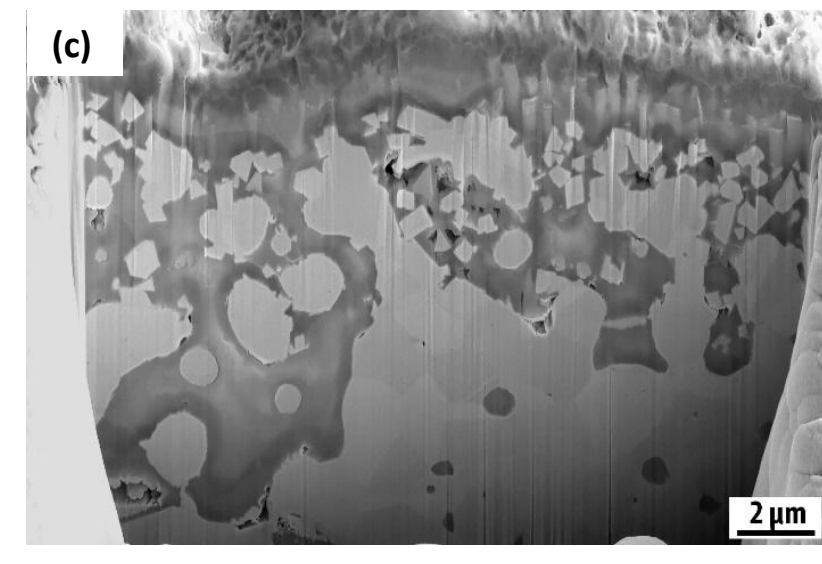

\section{(b)}

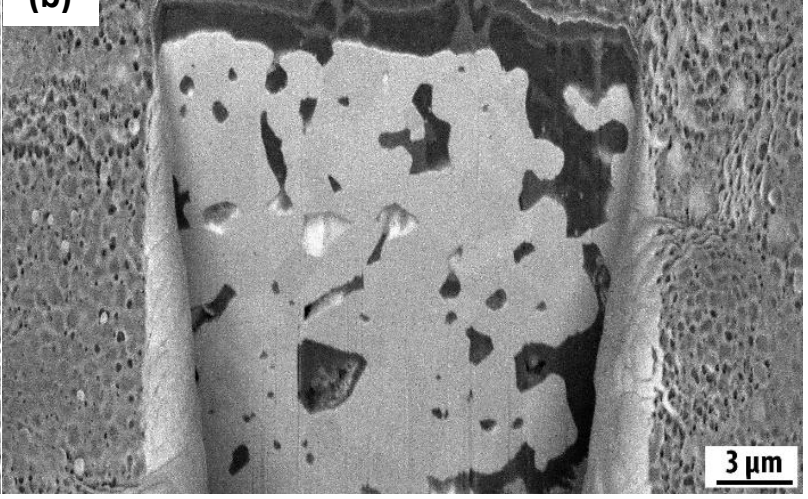

(d)
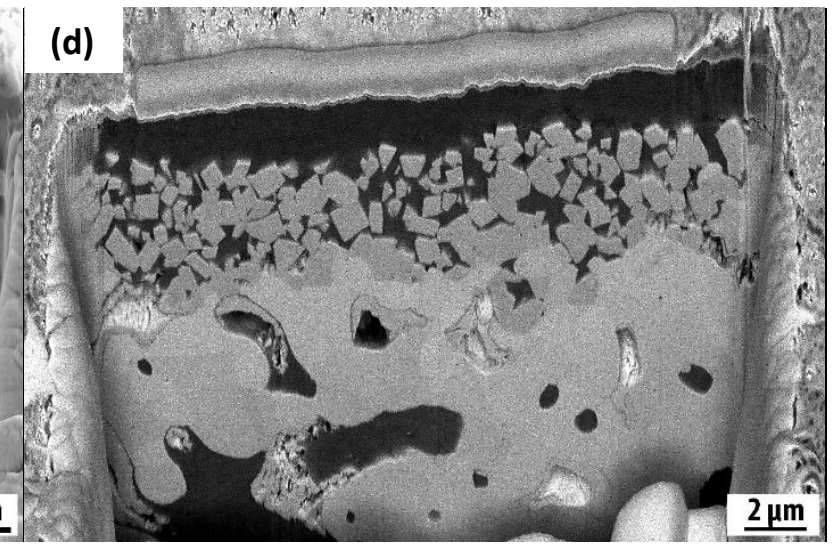


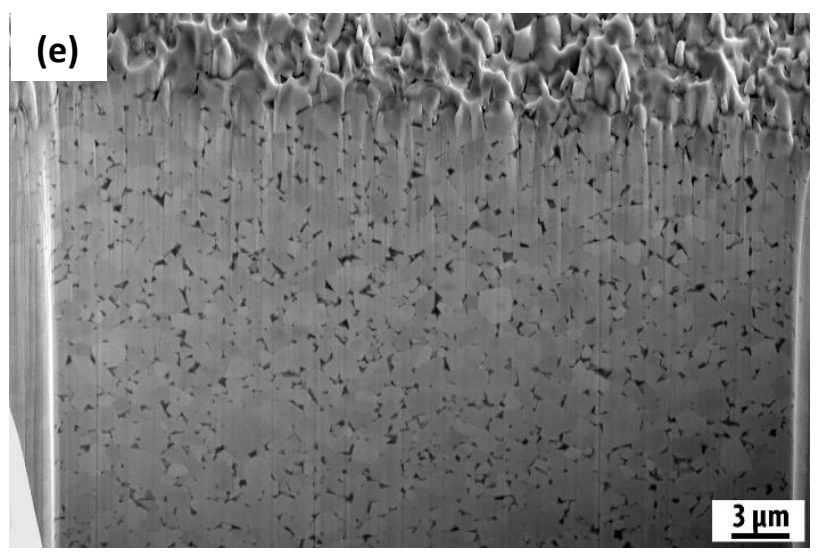

Figure 1 The SEM micrographs of FIB cross section of the sheets with 17.3 wt.\% of lithium carbonate, heated up to $900{ }^{\circ} \mathrm{C}$ at (a) carbon dioxide, (b)nitrogen, (c) $0.02 \%$ oxygen (c) $0.04 \%$ oxygen, and (d) air.

A detailed study on the $\mathrm{Li}_{2} \mathrm{CO}_{3}$ decomposition and carbon re-deposition vs. temperature at $0.04 \%$ oxygen flow is given in Supporting Information.

\section{2 $\mathrm{Li}^{+}$effect and distribution}

The second mechanism for reducing resistivity is the $\mathrm{Li}^{+}$doping effect, as discussed in the introduction. In order to illustrate the $\mathrm{Li}^{+}$contribution, two sheets with similar microstructure were selected. The first sheet was made of coated particles and sintered at $1330^{\circ} \mathrm{C}$ for 3 minutes at $0.04 \%$ oxygen, and the other one was made of uncoated particles and sintered in the same program but at $0.02 \%$ oxygen. Their microstructures are presented in Figure 2 (a) and (b); there is NiO layer on the top of both sheets, with the minimum thickness of 2.0 and $1.3 \mu \mathrm{m}$, respectively. Both sheets have a similar microstructure, in the sense that both have a NiO layer on top. Although the NiO layer is thicker on top of the sheet with $\mathrm{Li}_{2} \mathrm{CO}_{3}$, its resistance was measured as $43 \Omega$, while the resistance of the sheet without $\mathrm{Li}_{2} \mathrm{CO}_{3}$ was measured as $140 \mathrm{k} \Omega^{13}$. A four orders of magnitude decrease in resistance in the sheets with a similar microstructure comes from the $\mathrm{Li}^{+}$doping effect. The microstructure of the coated particles were further investigated in the Supporting Information (Figure S2). 


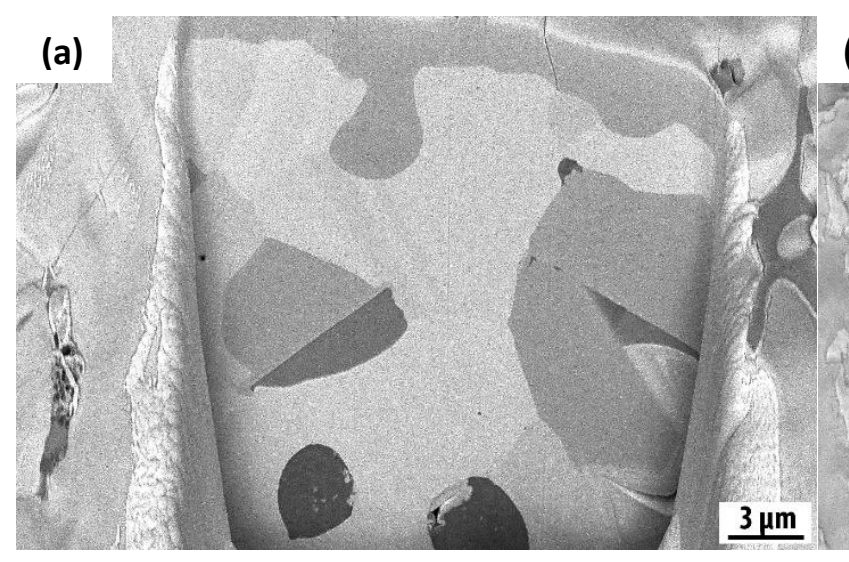

(b)

Figure 2 SEM micrographs of FIB cross section in the sheets, made of (a) coated particles and sintered in $1330^{\circ} \mathrm{C}$ for three minutes at $0.04 \%$ oxygen (b) uncoated particles and sintered in the same sintering program but at $0.02 \%$ oxygen.

The other observation in Figure 2 (a) is that the final microstructure of coated particles is a mixture of $\mathrm{Ni}$ and $\mathrm{NiO}$ grains with some black islands; that type of microstructure was also noted in the previous paper $^{13}$. Figure 3 shows one of the islands in its matrix together with its EDS (energy dispersive spectroscopy) analysis. As Figure 3 (a) shows, the matrix is made of $\mathrm{Ni}$ and $\mathrm{NiO}$ grains, and the island is made of a mixture of oxygen, carbon, and lithium and would be called LiCO area. The EDS map of Figure 3 (a) is shown in Supporting Information. The map shows that there is a mixture of $\mathrm{Ni}$ and $\mathrm{C}$ at the border of the island, suggesting the interdiffusion of the island and the matrix.

Figure 3 (b) shows the LiCO area in a higher magnification, and its EDS maps are presented in Figure 3 (ce). The EDS analysis suggests that there is not a detectable amount of $\mathrm{Ni}$ in LiCO region, and the amounts of oxygen and carbon are not uniformly distributed in the LiCO region. In order to quantitatively show the distribution of carbon and oxygen, an EDS line-scan and the molar ratio of carbon over oxygen, based on EDS data, are presented in Figure $3(\mathrm{f})$ and $(\mathrm{g})$, respectively. The line-scan data come from the line, shown in Figure 3 (b) and labeled as 'EDS line scan'. Three regions are detectable: carbon-rich, $\mathrm{Li}_{2} \mathrm{CO}_{3}$, and carbon-depleted. These three areas can be located, based on Figure 3 (g), where some areas are above, below, or on the line of $1 / 3$ molar ratio of carbon over oxygen. Since we are certain that the atoms in LiCO region are limited to $L i, C$, and $O$ (the existence of $L i$ would be demonstrated by EELS later), one can argue that all the plausible solid phases are $\mathrm{Li} 2 \mathrm{O}, \mathrm{Li}_{2} \mathrm{CO}_{3}$, and pure 
carbon. By considering the cooling rate of $-50{ }^{\circ} \mathrm{C} / \mathrm{min}$ in the heat treatments and eutectic reaction at $705{ }^{\circ} \mathrm{C}$ in $\mathrm{Li}_{2} \mathrm{O}$ and $\mathrm{Li}_{2} \mathrm{CO}_{3}$ phase diagram ${ }^{36}$, one can argue that the $\mathrm{LiCO}$ area is made up of nonequilibrium phases of $\mathrm{Li}_{2} \mathrm{O}$ and $\mathrm{Li}_{2} \mathrm{CO}_{3}$, with some rich carbon areas due to the carbon re-deposition.
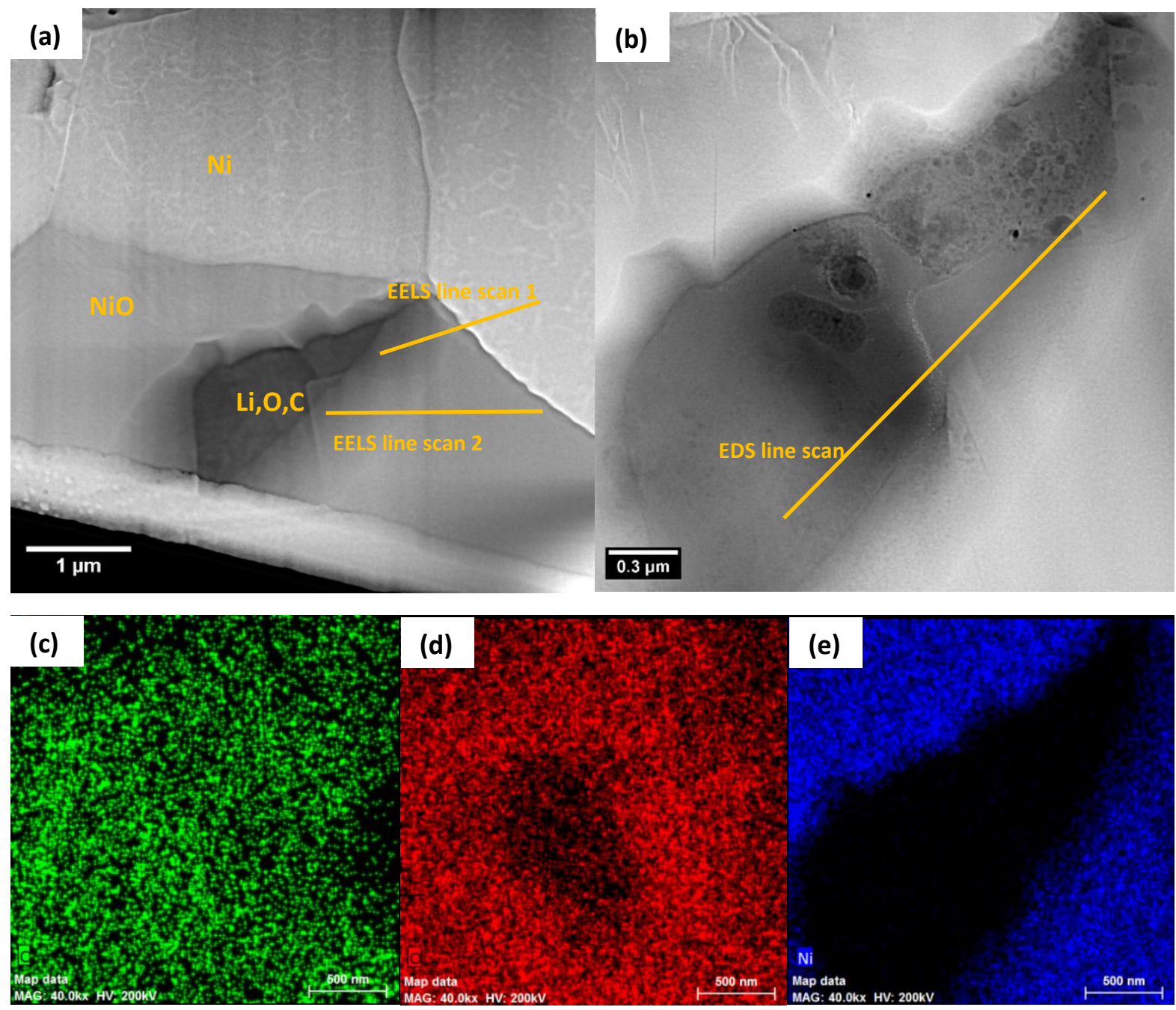

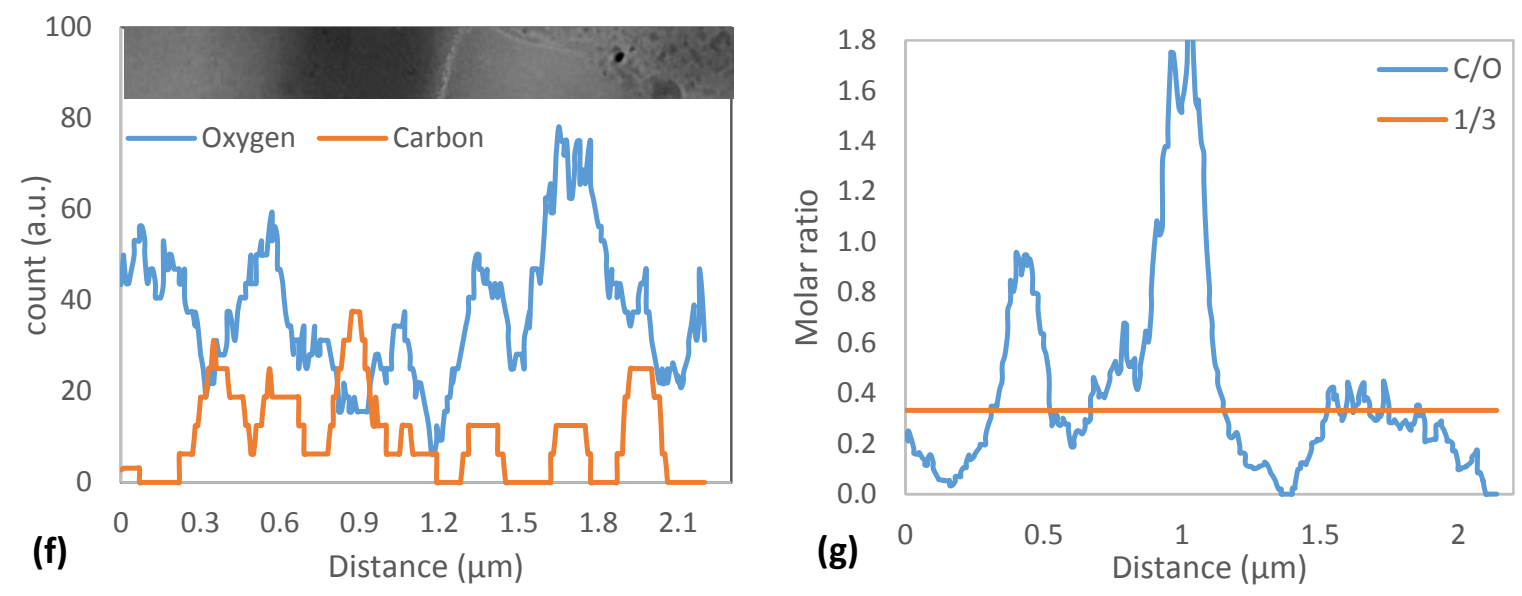

Figure 3 (a), (b) STEM-Dark Field micrographs of the Ni sheet with 17.3 wt. $\% \mathrm{Li}_{2} \mathrm{CO}_{3}$ sintered in $1330-3$ in $0.04 \%$ of oxygen flow. The EDS map of (c) carbon, (d) oxygen, and (e) nickel from the area, shown in figure (b). (f) intensity (g) molar ratio of carbon over oxygen vs distance on the line, showed in figure (b). The EELS line scan 1 and 2 are the lines, where EELS analysis in Figure 4 (a) and (c) were done.

The LiCO islands were separated from each other and made a small portion of the microstructure, while the matrix (i.e. the continuous phase) was made of $\mathrm{Ni}-\mathrm{NiO}$ grains, as shown in Figure 2 (a) and Figure 3 (a). So the most of the electron conductivity happened through the matrix, whose conductivity was determined by $\mathrm{Li}^{+}$concentration and $\mathrm{Ni}^{3+} / \mathrm{Ni}^{2+}$ ratio.

Two sets of data, $\mathrm{Li}^{+}$distribution and $\mathrm{Ni}^{3+} / \mathrm{Ni}^{2+}$ ratio, can be provided by EELS analysis. Figure 4 (a) presents the intensity of $\mathrm{Li}^{+}$edge vs. distance on the line, labeled as 'EELS line-scan $1^{\prime}$ in Figure 3 (a). The intensities suggest that the $\mathrm{Li}^{+}$concentration is maximum at the border of the LiCO island and decrease with distance from it. By passing the $\mathrm{Ni}-\mathrm{NiO}$ grain boundary, the intensity becomes considerably low, indicating $\mathrm{Li}^{+}$concentration is negligible in Ni grains. To verify this conclusion, four spectrums of EELS analysis at different points are shown in Figure 4 (b). As discussed in literatures, Li K-edge can be shifted from 54.7 to $61 \mathrm{eV}$ for different $\mathrm{Li}$ bonding ${ }^{37-39}$, and $\mathrm{Ni}$ has its $\mathrm{M}_{2,3}$ edge at $68 \mathrm{eV}^{37}$. As can be seen, two edges can be detected at 58.5 and $65 \mathrm{eV}$ in spectrum (1), (2), and (3), which are collected from $\mathrm{NiO}$ grain. The place of these points are marked in Figure 4 (a). The spectrum (1) to (3) can be a signature for $\mathrm{Ni}, \mathrm{Li}$, and $\mathrm{O}$ coexistence. The concentration of $\mathrm{Li}$ was related to the intensity of the edge at $58.5 \mathrm{eV}$. As 
illustrated in spectrum (4), $\mathrm{Li}^{+}$edge becomes negligible in the $\mathrm{Ni}$ grain and the $\mathrm{Ni} \mathrm{M}_{2,3}$ edge shift from 65 $\mathrm{eV}$ back to $68 \mathrm{eV}$.

The other set of experiments is core-loss EELS and collecting Ni energy loss at 845 and $874 \mathrm{eV}$. The ratio of the intensity of the second edge over the intensity of the first edge, shown by R in this paper, is equivalent to the $\mathrm{Ni}^{3+}$ concentration over $\mathrm{Ni}^{2+}$ concentration $22,40,41$. So one would be able to trace $\mathrm{Ni}^{3+} / \mathrm{Ni}^{2+}$ ratio by EELS analysis, as demonstrated in the previous work ${ }^{25}$. The significance of $\mathrm{Ni}^{3+} / \mathrm{Ni}^{2+}$ in Ni conductivity was discussed in Introduction and the previous work ${ }^{25}$.

Figure 4 (c) presents R vs. distance; the EELS data were collected on the line, labeled as 'EELS line-scan 2' in Figure 3 (a). A comparison between Figure 4 (a) and (c) suggests that the ratio of $\mathrm{Ni}^{3+} / \mathrm{Ni}^{2+}$ increased by increasing $\mathrm{Li}^{+}$concentration except near the island, where Li concentration exponentially increased, while $\mathrm{R}$ ratio reached a plateau at 0.45 . This upper limit can be justified as the state in which all of the $\mathrm{Ni}^{2+}$ ions convert to $\mathrm{Ni}^{3+}$ to compensate the charge offset due to $\mathrm{Li}^{+}$introduction. On the other hand, there is a lower limit for $\mathrm{R}$, where stoichiometric $\mathrm{NiO}$ with minimum $\mathrm{Ni}^{3+}$ was tested. The lower limit of $\mathrm{R}$ was reported as 0.25 by the authors ${ }^{25}$ and Muto et al. ${ }^{40}$ As can be seen, every point in the curve of Figure 4 (c) is above the lower limit. One may conclude that $\mathrm{Li}^{+}$, even in low concentration, can effectively increase $\mathrm{Ni}^{3+}$ in the entire $\mathrm{NiO}$ grain. Three typical spectra were selected from the line scan in Figure 4 (c) and are presented in Figure 4 (d). Spectrum (1) is a typical spectrum, which can be found near the LiCO island and since the $\mathrm{Ni}$ is diluted by carbon and lithium, its edge intensity is low. By going away from the island, the spectrum evolved to (2) and (3), and the edge intensity increased due to increase of $\mathrm{Ni}$ concentration. However, as explained above, we are interested in the $\mathrm{R}$ and $\mathrm{Ni}^{3+} / \mathrm{Ni}^{2+}$ ratio.

Now, one can have a complete image of the electron conductivity in the sheets. The conductivity occurred through the continuous matrix of $\mathrm{Ni}$ and $\mathrm{NiO}$ grains. Electrons can easily transfer through $\mathrm{Ni}$ 
metallic grains, and when they reach the Li doped $\mathrm{NiO}$ grains, the electrons can still pass them without much increase in resistivity through the polaron hopping process. This mechanism can justify the decline in the resistance of the sheets, shown in Figure 2, from $140 \mathrm{k} \Omega$ to $43 \Omega$.
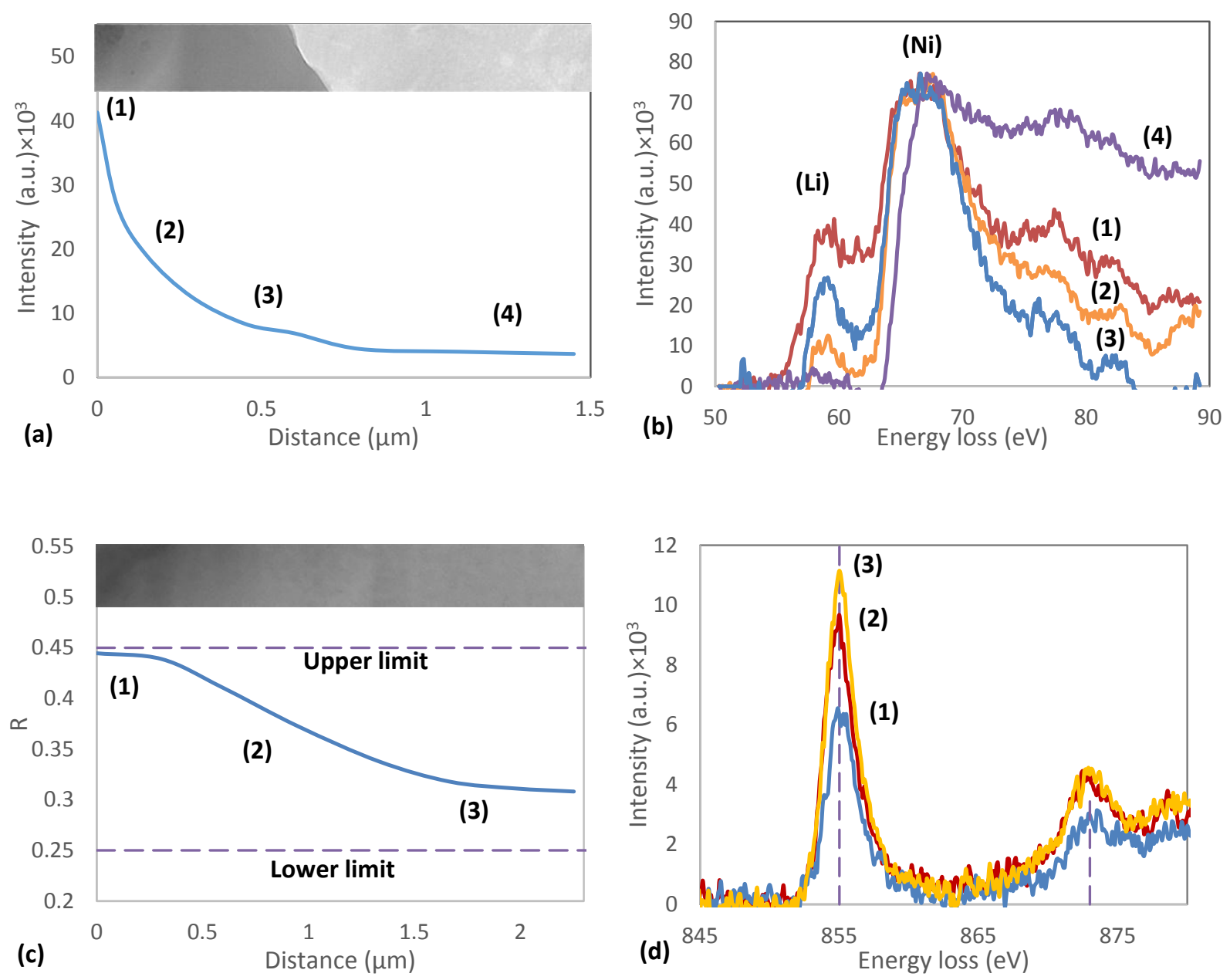

Figure 4 (a) the intensity of Li edge and (c) the ratio of second edge over the first edge in Ni spectrums (shown as R) vs distance along with the image, where the analysis were executed. Typical spectrums in line scan of (a) and (c) are shown in (b) and (d) respectively.

\subsection{The effect of lithium carbonate decomposition on conductivity preservation}

The influence of $\mathrm{Li}^{+}$is shown in the previous section specifically by comparing the two cases in Figure 2 .

It would be informative to repeat the same experiment with and without the effect of $\mathrm{Li}_{2} \mathrm{CO}_{3}$ decomposition. In order to do so, $\mathrm{CO}_{2}$ gas was utilized during sintering. As suggested previously, $\mathrm{CO}_{2}$ can 
preserve $\mathrm{Li}_{2} \mathrm{CO}_{3}$, and at the same time, burn out all residual carbon. Thus, without the residual carbon, the sintering atmosphere would be $\mathrm{CO}_{2}$ gas (with a purity of $99.99 \%$ ) without any reducing agents (i.e., CO). The coated particles were sintered at $1330^{\circ} \mathrm{C}$ for 3 minutes in $\mathrm{CO}_{2}$ gas and, afterward, their resistance was measured as $1.2 \mathrm{k} \Omega$, while the resistance of uncoated particles was measured as $80 \mathrm{k} \Omega$. One can argue that this decrease in resistance is only due to the $\mathrm{Li}^{+}$-doping effect.

One can argue that the coated particles sintered at $\mathrm{CO}_{2}$ atmosphere can be compared with the coated particles sintered in $0.02 \%$ oxygen balanced with nitrogen. The atmosphere with $0.02 \%$ oxygen possessed a higher oxygen content than the $\mathrm{CO}_{2}$ atmosphere since the $\mathrm{CO}_{2}$ gas only had a $0.01 \%$ impurity comprised of oxidizing agents. In addition, the resistance of uncoated particles, after sintering in the $\mathrm{CO}_{2}$ and $0.02 \%$ oxygen, were measured as 80 and $140 \mathrm{k} \Omega$, respectively. Thus, the $0.02 \%$ oxygen atmosphere is more oxidizing than the $\mathrm{CO}_{2}$ atmosphere.

Next, the coated particles were sintered in the $0.02 \%$ oxygen atmosphere, and their resistance was measured as $10 \Omega$. This value is two orders of magnitude less than the $1.2 \mathrm{k} \Omega$ resistance of the $\mathrm{CO}_{2}$ sintered sheet. Furthermore, the FIB cross section of the $\mathrm{CO}_{2}$-sintered sheet, presented in Figure S5, showed a thick NiO layer of $1.5 \mu \mathrm{m}$ on the top of the sheet. However, this layer would be negligible in $0.02 \%$ oxygen with the average thickness of $0.1 \mu \mathrm{m}$ as shown in Figure S4 (The effect of the $\mathrm{Li}_{2} \mathrm{CO}_{3}$ decomposition on NiO layers were further investigated in the previous paper ${ }^{13}$ ). It can be concluded that although $0.02 \%$ oxygen is more oxidizing than the $\mathrm{CO}_{2}$ atmosphere, the coated particle would have less $\mathrm{NiO}$ phase and consequently less resistance due to the decomposition of $\mathrm{Li}_{2} \mathrm{CO}_{3}$ and the production of CO gas.

\section{Conclusions}

Coating $\mathrm{Ni}$ particles with $\mathrm{Li}_{2} \mathrm{CO}_{3}$ can preserve the electrical conductivity of the resultant electrode in more oxidative atmospheres during sintering which can offer significant improvements in 
electroceramic processing and electrical properties by limiting the concentration of oxygen vacancies. In this study, the underlying mechanisms in the process of conductivity preservation were explored and understood. Two mechanisms of $\mathrm{Li}^{+}$doping and $\mathrm{Li}_{2} \mathrm{CO}_{3}$ decomposition were introduced, and their effects on conductivity preservation were studied independently. It was shown that the $\mathrm{Li}_{2} \mathrm{CO}_{3}$ melted and flew around the Ni grains; at the same time, it decomposed into $\mathrm{CO}$ gas. The $\mathrm{CO}$ acted as a reducing agent and could hinder the $\mathrm{NiO}$ formation. In addition, a layer of carbon on the sheets was the result of $\mathrm{CO}$ gas existence; its thickness was found to be dependent on oxygen percentage and temperature. It was demonstrated that by applying $\mathrm{CO}_{2}$ gas during the sintering process, the reducing effect of $\mathrm{CO}$ gas could be eliminated and, as a result, the resistance increased from $10 \Omega$ to $1.2 \mathrm{k} \Omega$ in the same concentration of $\mathrm{Li}^{+}$.

The final microstructure of the sheets was a matrix of $\mathrm{Ni}$ and $\mathrm{NiO}$ grains with islands of residual $\mathrm{Li}_{2} \mathrm{CO}_{3}$. The distribution of ions were mapped for this microstructure. The $\mathrm{Ni}^{3+} / \mathrm{Ni}^{2+}$ ratio, which controls electron hopping and resistivity reduction in $\mathrm{NiO}$ phases was also measured. Two similar microstructures, with and without $\mathrm{Li}^{+}$, were selected, and it was shown that the Li doping effect can decrease the resistance from $140 \mathrm{k} \Omega$ to $43 \Omega$.

Both previous observations suggested that the $\mathrm{Li}^{+}$doping effect and the production of $\mathrm{CO}$ gas were both relevant in preserving the electrical conductivity. The $\mathrm{CO}$ gas, as a reducing agent, decreased the amount of $\mathrm{NiO}$ phases and hence the oxidation of metallic $\mathrm{Ni}$, while the $\mathrm{Li}^{+}$doping decreased the resistance via increasing the $\mathrm{Ni}^{3+} / \mathrm{Ni}^{2+}$ ratio. The combination of both mechanisms resulted in a fiveorders-of-magnitude decrease in the resistance of the sheets.

\section{Acknowledgements}

This material is based upon work supported by the National Science Foundation I/UCRC, as part of the Center for Dielectric and Piezoelectrics (CDP) under Grant Nos. IIP- 1361503 and 1361571 . We thank the 
members for many useful conversations, especially from Dr. Larry Mann of Shoei Chemical. In addition, the authors like to acknowledge Dr. Trevor Clark and Dr. Bernd Kabius in Material Characterization Laboratory at the Pennsylvania State University for their consultations.

\section{References}

${ }^{1}$ C.A. Randall, A. Kelnberger, G.Y. Yang, R.E. Eitel, and T.R. Shrout, J. Electroceramics 14, 177 (2005).

${ }^{2}$ K. Kobayashi, Y. Doshida, Y. Mizuno, and C.A. Randall, J. Am. Ceram. Soc. 95, 2928 (2012).

${ }^{3}$ S. Kawada, M. Kimura, Y. Higuchi, and H. Takagi, Appl. Phys. Express 2, 111401 (2009).

${ }^{4}$ A. Müller, D. Herbstritt, and E. Ivers-Tiffée, Solid State Ionics 152-153, 537 (2002).

${ }^{5}$ Z. Wang, J. Qian, J. Cao, S. Wang, and T. Wen, J. Alloys Compd. 437, 264 (2007).

${ }^{6}$ G.Y. Yang, G.D. Lian, E.C. Dickey, C.A. Randall, D.E. Barber, P. Pinceloup, M.A. Henderson, R. a. Hill, J.J. Beeson, and D.J. Skamser, J. Appl. Phys. 96, 7500 (2004).

${ }^{7}$ H. Kishi, Y. Mizuno, and H. Chazono, Jpn. J. Appl. Phys. 42, 1 (2003).

8 J. Yamamatsu, N. Kawano, T. Arashi, A. Sato, Y. Nakano, and T. Nomura, J. Power Sources 60, 199 (1996).

${ }^{9}$ D.S. Baba Heidary, W. Qu, and C.A. Randall, RSC Adv. 5, 50869 (2015).

${ }^{10}$ D. Sohrabi Baba Heidary and C.A. Randall, Acta Mater. 96, 344 (2015).

${ }^{11}$ D. Sohrabi Baba Heidary, W. Qu, and C.A. Randall, J. Appl. Phys. 117, 124104 (2015).

${ }^{12}$ D. Sohrabi Baba Heidary and C.A. Randall, Scr. Mater. 107, 30 (2015).

${ }^{13}$ D.S.B. Heidary and C.A. Randall, Chem. Eng. J. (2016). 
${ }^{14}$ J.-W. Kim and H.-G. Lee, Metall. Mater. Trans. B 32, 17 (2001).

${ }^{15}$ W. Janosik, C.A. Randall, and M. Lanagan, J. Am. Ceram. Soc. 90, 2415 (2007).

${ }^{16}$ H.G. Kim, J.-I. Park, and G.H. Lee, Mater. Chem. Phys. 140, 419 (2013).

${ }^{17}$ P. Lunkenheimer, A. Loidl, C. Ottermann, and K. Bange, Phys. Rev. B 44, 2 (1991).

18 J. Honig, J. Chem. Educ. 43, 76 (1966).

${ }^{19}$ D. Snowden and H. Saltsburg, Phys. Rev. Lett. 1, 13 (1965).

${ }^{20}$ N. Nasu, K. Tsuda, A. Siratori, and K. Fujimori, Electronic Conduction in Oxides (Springer, Berlin, 2000).

${ }^{21}$ E. Antoini, J. Mater. Sci. 27, 3335 (1992).

${ }^{22}$ G. Tyuliev and M. Sokolova, Appl. Surf. Sci. 52, 343 (1991).

${ }^{23}$ K. Voleník, P. Ctibor, J. Dubský, P. Chráska, and J. Horák, Czechoslov. J. Phys. 54, C889 (2004).

${ }^{24}$ I.G. Austin and N.F. Mott, Adv. Phys. 50, 757 (2001).

${ }^{25}$ D. Sohrabi Baba Heidary and C.A. Randall, Nanotechnology 27, 245701 (2016).

${ }^{26}$ R.D. Shannon, Acta Crystallogr. Sect. A 32, 751 (1976).

${ }^{27}$ S. Van Houten, J. Phys. Chem. Solids 23, 1045 (1962).

${ }^{28}$ W. Guo, K.N. Hui, and K.S. Hui, Mater. Lett. 92, 291 (2013).

${ }^{29}$ A. Polotai, K. Breece, E. Dickey, C. Randall, and A. Ragulya, J. Am. Ceram. Soc. 88, 3008 (2005).

${ }^{30}$ H. Beyer, S. Meini, N. Tsiouvaras, M. Piana, and H. a. Gasteiger, Phys. Chem. Chem. Phys. 15, 11025 (2013).

${ }^{31}$ N.J. Donnelly, T.R. Shrout, and C.A. Randall, J. Am. Ceram. Soc. 92, 1203 (2009).

${ }^{32}$ Y.-D. Hou, L.-M. Chang, M.-K. Zhu, X.-M. Song, and H. Yan, J. Appl. Phys. 102, 084507 (2007).

${ }^{33}$ Y. Yang, W. Li, and H. Xu, React. Kinet. Catal. Lett. 77, 155 (2002).

${ }^{34}$ V. Duboviks, R.C. Maher, M. Kishimoto, L.F. Cohen, N.P. Brandon, and G.J. Offer, Phys. Chem. Chem. Phys. 16, 13063 (2014).

${ }^{35}$ T. Baird, J.R. Fryer, and B. Grant, Carbon N. Y. 12, 591 (1974). 
${ }^{36}$ M. V. Smirnov, I.Y. Lyubimtseva, L.A. Tsiovkina, and Y.N. Krasnov, ZHURNAL Neorg. KHIMII 16, 251 (1971).

${ }^{37}$ C.C. Ahn and O.L. Krivanek, EELS Atlas: A Reference Collection of Electron Energy Loss Spectra Covering All Stable Elements (Gatan, Pleasanton, 1983).

${ }^{38}$ F. Wang, J. Graetz, M.S. Moreno, C. Ma, L. Wu, V. Volkov, and Y. Zhu, ACSNano 5, 1190 (2011).

${ }^{39}$ F. Cosandey, Microsc. - Sci Technol Appl Educ 3, 1662 (2010).

${ }^{40}$ S. Muto, Y. Sasano, K. Tatsumi, T. Sasaki, K. Horibuchi, Y. Takeuchi, and Y. Ukyo, J. Electrochem. Soc. 156, A371 (2009).

${ }^{41}$ C.C. Ahn, Transmission Electron Energy Loss Spectrometry in Materials Science and the EELS Atlas (Wiley-VCH, Weinheim, 2004). 
Graphical Abstract

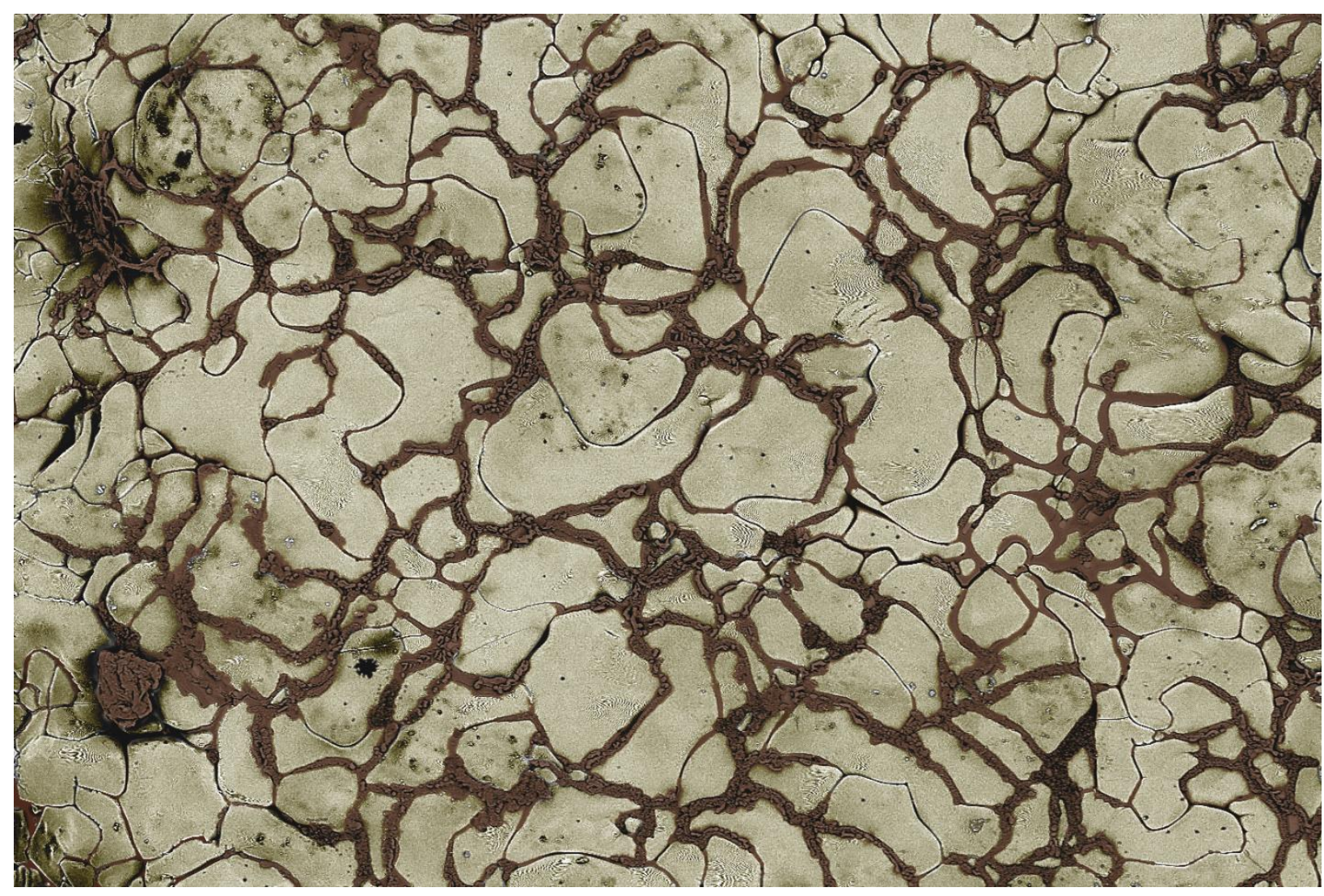

The lithium carbonate coating melts and surrounds Ni particles in early stage of sintering and preserves their electrical conductivity during the sintering in oxidizing atmospheres. The micrograph shows the Ni particles, enclosed with lithium carbonate residues, after sintering. 